\title{
Gastrointestinal Physiology
}

National Cancer Institute

\section{Source}

National Cancer Institute. Gastrointestinal Physiology. NCI Thesaurus. Code C18802.

The science concerned with the normal processes of the stomach and intestines and how they are affected by drugs or disease. 